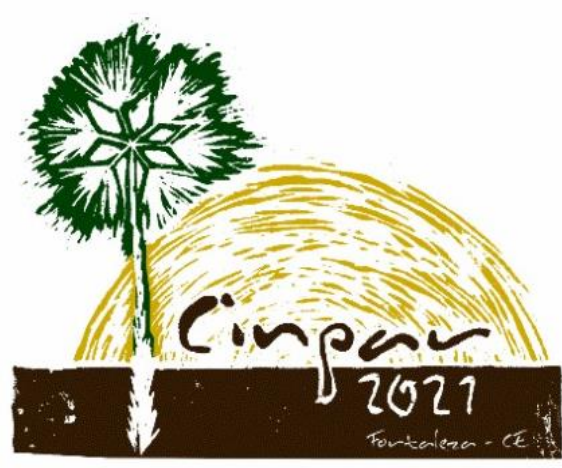

XVII Congresso Internacional sobre Patologia e

Reabilitação das Construções

XVII Congreso Internacional sobre Patología y Rehabilitación de las Construcciones

XVII International Conference on Pathology and Constructions Rehabilitation

FORTALEZA (Brasil), 3 a 5 de junho de 2021

https://doi.org/10.4322/CINPAR.2021.006

\title{
Corrosão na Armadura em Estruturas de Concreto Armado Devido ao Ataque de Sulfatos
}

\section{Reinforcement corrosion in Reinforced Concrete Structures due to sulfate attack}

\author{
Henrique Resende SANTOS ${ }^{1}$, Adriano de Paula e SILVA ${ }^{2}$, Eduardo CHAHUD $^{3}$ \\ ${ }^{1}$ Universidade Federal de Minas Gerais, Belo Horizonte, Brasil, henriqueresendesantos@gmail.com \\ ${ }^{2}$ Universidade Federal de Minas Gerais, Belo Horizonte, Brasil, apsilva@demc.ufmg.br \\ ${ }^{3}$ Universidade Federal de Minas Gerais, Belo Horizonte, Brasil, chahud@demc.ufmg.br
}

\begin{abstract}
Resumo: Este trabalho apresenta um estudo bibliográfico sobre a corrosão das armaduras de estruturas de concreto armado provocada pela ação dos íons sulfatos. Foi analisado o meio em que os íons sulfatos estavam inseridos, bem como as variáveis que interferem neste processo para causar deterioração nas estruturas de concreto armado. Pode-se concluir com este trabalho que, além de provocar reações químicas expansivas no concreto, o ataque de sulfatos também pode ocasionar corrosão nas armaduras sendo essencial ampliar o conhecimento do mecanismo de ação para condutas preventivas e corretivas no intuito de aumentar a vida útil das estruturas de concreto armado.
\end{abstract}

Palavras-chave: Corrosão das armaduras. Íons Sulfatos. Concreto.

\begin{abstract}
This work presents a bibliographic study on the corrosion of reinforced concrete structures reinforcement caused by the action of sulfate ions. The medium in which the sulfate ions were inserted was analyzed, as well as the variables that interfere in this process to cause deterioration in the reinforced concrete structures. It can be concluded with this work that, in addition to causing expansive chemical reactions in the concrete, the attack of sulfates can also cause corrosion in the reinforcement, being essential to expand the knowledge of the mechanism of action for preventive and corrective conducts in order to increase the useful life of the reinforced concrete structures.
\end{abstract}

Keywords: Corrosion of reinforcement. Sulfate ions. Concrete.

\section{Introdução}

Conforme Petru (2019), as estruturas estão sempre em contato com os efeitos deletérios, tais como, sobrecargas, ataques ambientais, desastres, entre outros. Segundo Glasser et.al. (2008), as estruturas de cimento Portland devem cumprir as funções prescritas em projeto, além de resistir à ação de agentes agressivos decorrente do ambiente no qual está inserido. Assim, as especificações dos materiais utilizados na execução estão intrinsecamente ligados à agressividade do meio durante à sua vida útil.

$\mathrm{O}$ concreto, quando corretamente executado, protege a armadura sobre dois principais aspectos: o físico e o químico. A proteção física é devido ao cobrimento do concreto que deve ser de acordo com a NBR 6118:2014, já a proteção química, é decorrente do meio alcalino, fazendo com que haja a formação de uma película fina, a camada passivadora (GENTIL, 1996). 
Segundo Moyses (2018), a camada passivadora é fundamental para não deixar o aço entrar em processo de corrosão. Além disso, Nascimento et al. (2020) mencionam que nas estruturas de concreto armado a corrosão das armaduras é uma das manifestações patológicas que ocorrem com maior frequência. 0 resultado desse processo eletroquímico é a redução da seção de armadura e a fissuração do concreto paralelamente a esta (MOTA et al. 2009).

No tocante à deterioração do concreto, esta acontece por fenômenos físico-químicos que apresentam causas diversas. Na figura 1 abaixo, Silva (2017) demonstrou as diversas formas de deterioração do concreto por reações químicas.

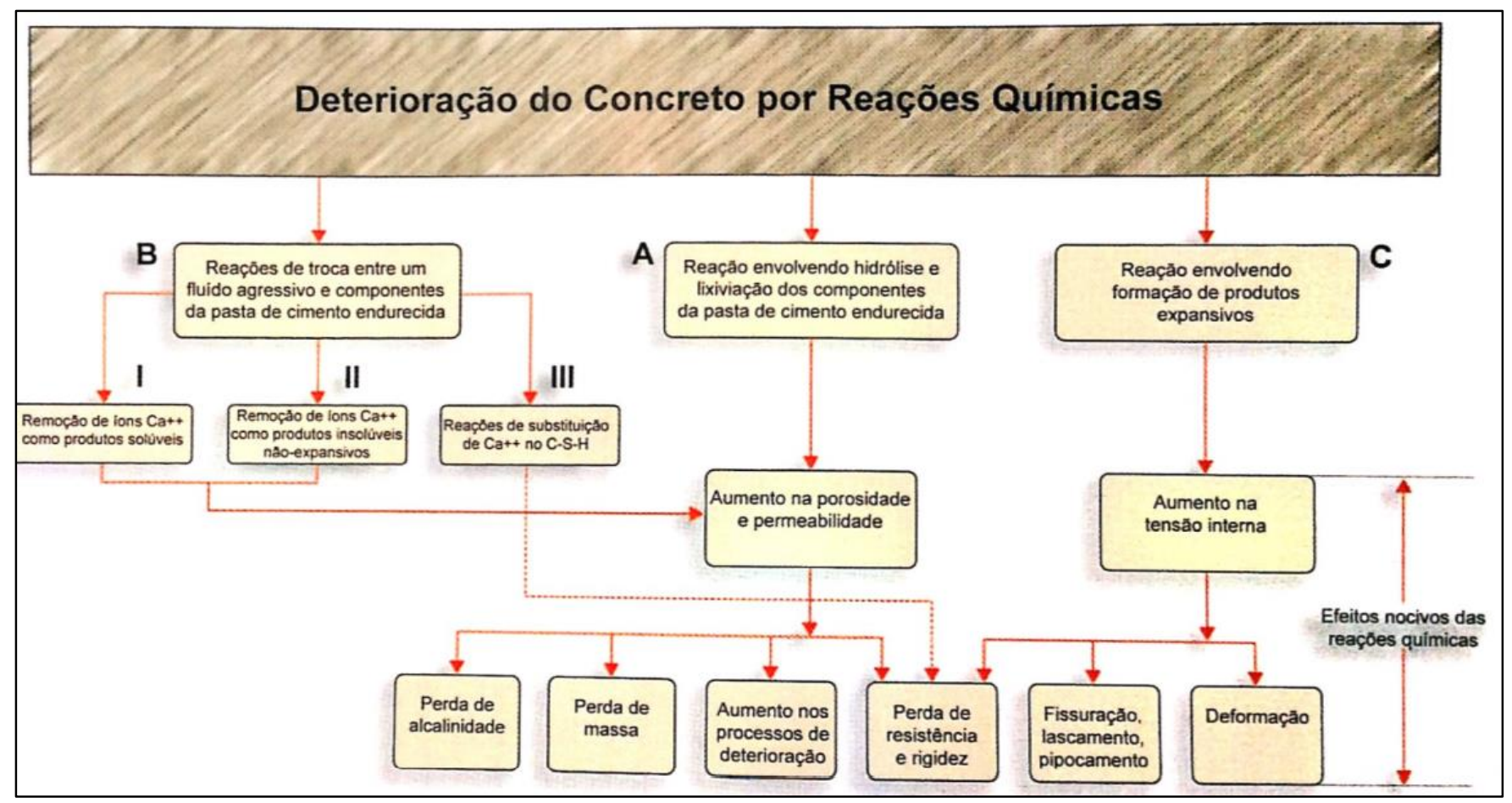

Figura 1 - Representação esquemática da deterioração do concreto por reações químicas (SILVA, 2017).

Os sulfatos estão entre os agentes químicos com maior agressividade sobre o material, podendo ser encontrados em diversas formas, como por exemplo, diluídos em água (Pereira, 2019). Deste modo, os concretos utilizados em obras subterrâneas, marítimas ou de condução de rejeitos industriais e esgotos são mais susceptíveis a esses ataques (Pereira, 2019).

$O$ ataque interno de sulfatos e os seus processos de formação e deterioração em compostos cimentícios são complexos, apesar de diversos estudos e discussões sobre o tema (DE LIMA e SILVA et al. 2018).

Segundo De Lima e Silva et al. (2018), os compostos hidratados da pasta endurecida e os íons sulfatos que estão presentes na solução dos poros da matriz, provocam várias reações químicas e físicas, resultando na formação de produtos que podem levar à expansão e à fissuração. Conforme relatam os mesmos autores, o ataque de sulfatos, notadamente o sulfato de magnésio, provoca a redução do pH no concreto, reduzindo a camada passivadora e, favorecendo o processo de corrosão.

Dessa forma, este trabalho tem como objetivo geral realizar uma revisão bibliográfica sobre a corrosão das armaduras em estruturas de concreto armado devido ao ataque de sulfatos.

Compreender como a durabilidade do concreto armado é afetada pelo ataque de sulfatos, demonstrando a atuação desse processo químico, é uma questão relevante para a construção civil. Neste sentido, estudos e pesquisas são constantemente desenvolvidos sobre as manifestações patológicas e a durabilidade das estruturas. Dependendo do tipo de solo, as fundações ficam em contato direto com águas ricas em sulfatos, o que pode acarretar em um impacto econômico na recuperação da edificação. Assim, a partir da ampla compreensão dos efeitos químicos gerados pelos sulfatos, pode-se evitar gastos elevados com a recuperação da estrutura. 
Este trabalho está organizado da seguinte forma: primeiro, há esta introdução, na qual é apresentada a contextualização e o objetivo; a segunda seção traz os mecanismos gerais da corrosão do aço no concreto; a terceira, por sua vez, apresenta as condições necessárias para o processo corrosivo; a quarta, se refere às estruturas de concreto e as procedências dos sulfatos; a quinta, é sobre a corrosão provocada pelos sulfatos e; a sexta e última, elenca as principais conclusões.

\section{Mecanismos Gerais}

Segundo Metha (2006), a corrosão do aço no concreto é um processo eletroquímico. Os potenciais eletroquímicos têm dois cominhos para formar as células de corrosão: incorporação de dois metais diferentes no concreto e, pela diferença de concentração de íons dissolvidos, tal como os álcalis.

Diante disso, forma-se no metal, uma área catódica e a outra anódica, conforme Figura 2 abaixo.

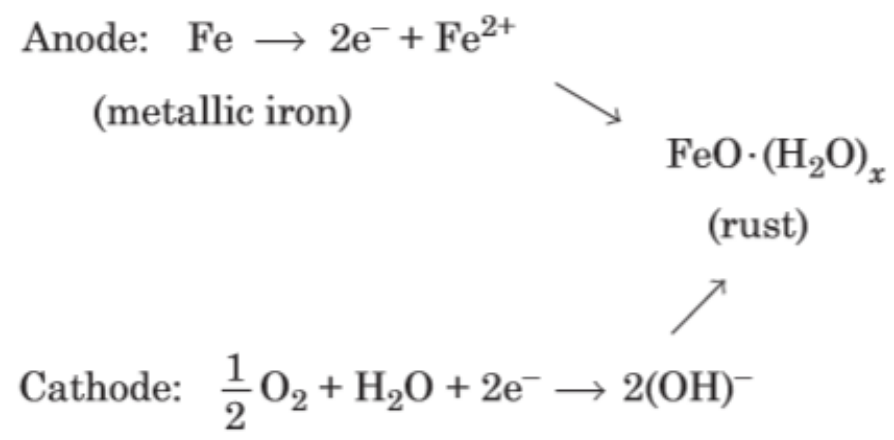

Figura 2 - Representação esquemática das alterações químicas (METHA, 2006).

A Figura 3 a seguir, demonstra que entre as áreas anódicas e catódicas haverá uma diferença de potencial (ddp), dando início ao fluxo de corrente elétrica, devido à formação do efeito pilha (FORTES; ANDRADE, 2001).

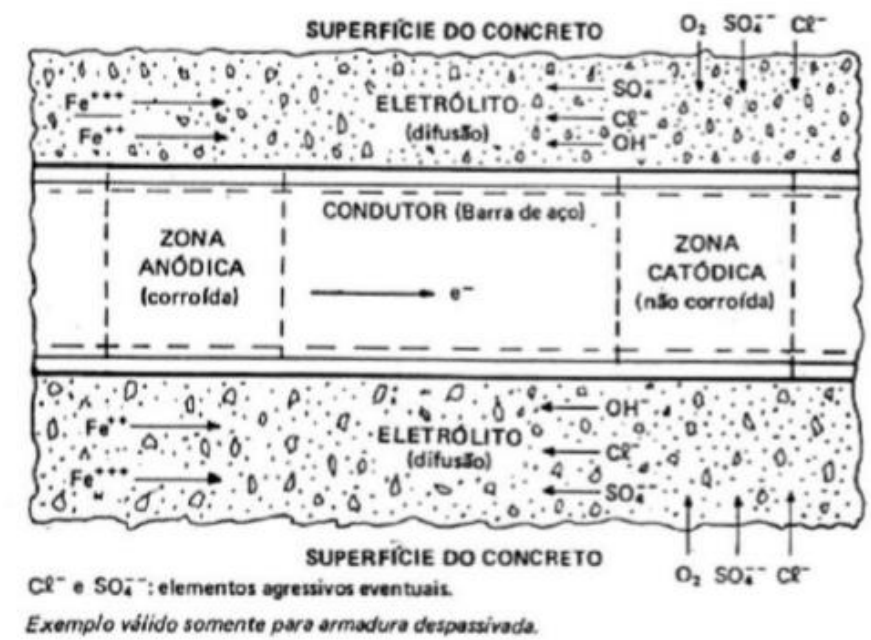

Figura 3 - Representação esquemática da corrosão eletroquímica em concreto armado (HELENE, 1986).

O fluxo de elétrons para a área catódica é mantido pelo consumo de elétrons, fazendo com que a ionização do ferro metálico aconteça na área anódica. Já em relação à área catódica, a presença do ar e da água na superfície do cátodo é extremamente necessário (METHA, 2006).

A formação da ferrugem decorrente da transformação ferro metálico, proporciona um aumento de volume, que dependendo do estado de oxidação, pode aumentar em até $600 \%$ do tamanho original, como mostra a Figura 4 a seguir (METHA, 2006). 


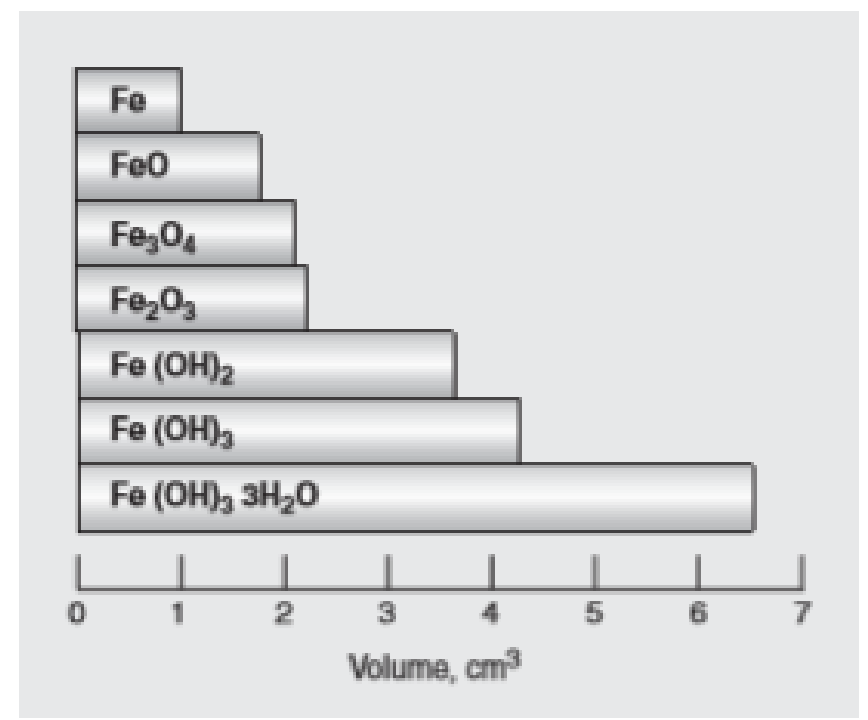

Figura 4 - Mostra que dependendo do estado de corrosão o volume sólido pode aumentar em até seis vezes (METHA, 2006)

A corrosão pode se manifestar no concreto armado na forma de manchas superficiais causadas pelos produtos de corrosão, seguidas por fissuras, destacamento do concreto de cobrimento, diminuição da seç̧ão resistente das armaduras com frequente seccionamento de estribos, redução e eventual perda de aderência das armaduras principais, ou seja, deteriorações que levam a um comprometimento da segurança estrutural (RIBEIRO, 2014).

\section{Condições necessárias para o processo corrosivo}

A formação de óxidos e hidróxidos de ferro é conduzida pela corrosão, produtos pulverulentos e porosos denominados ferrugem. Esses produtos só ocorrem nas seguintes condições: existência de um eletrólito; diferença de potencial; oxigênio e; agentes agressivos (HELENE, 1986).

O eletrólito tem como propósito permitir a dissipação e mobilidade dos íons, realizando a ligação entre a superfície do aço e a matriz porosa do concreto. A título de exemplo, a água existente no concreto em grande proporções funciona como um eletrólito. Além desta, a portlandita - $\mathrm{Ca}(\mathrm{OH}) 2-$, produto de hidratação do cimento, formam nos poros e capilares uma solução saturada que constitui um bom eletrólito (RIBEIRO, 2014).

A diferença de potencial é causada devido à diferença de potencial entre os pontos da barra, como por exemplo: diferença de umidade, aeração, concentração salina, tensão no concreto e no aço (RIBEIRO, 2014). Segundo Helene (1986), o oxigênio é necessário para a formação da ferrugem - $2 \mathrm{Fe}(\mathrm{OH}) 2$. Na Figura 5, aparesentada a seguir, a velocidade inicial é acelerada tendendo a decrescer com a constituição da camada de óxido, porque esta irá operar como um impedimento da difusão do oxigênio. 


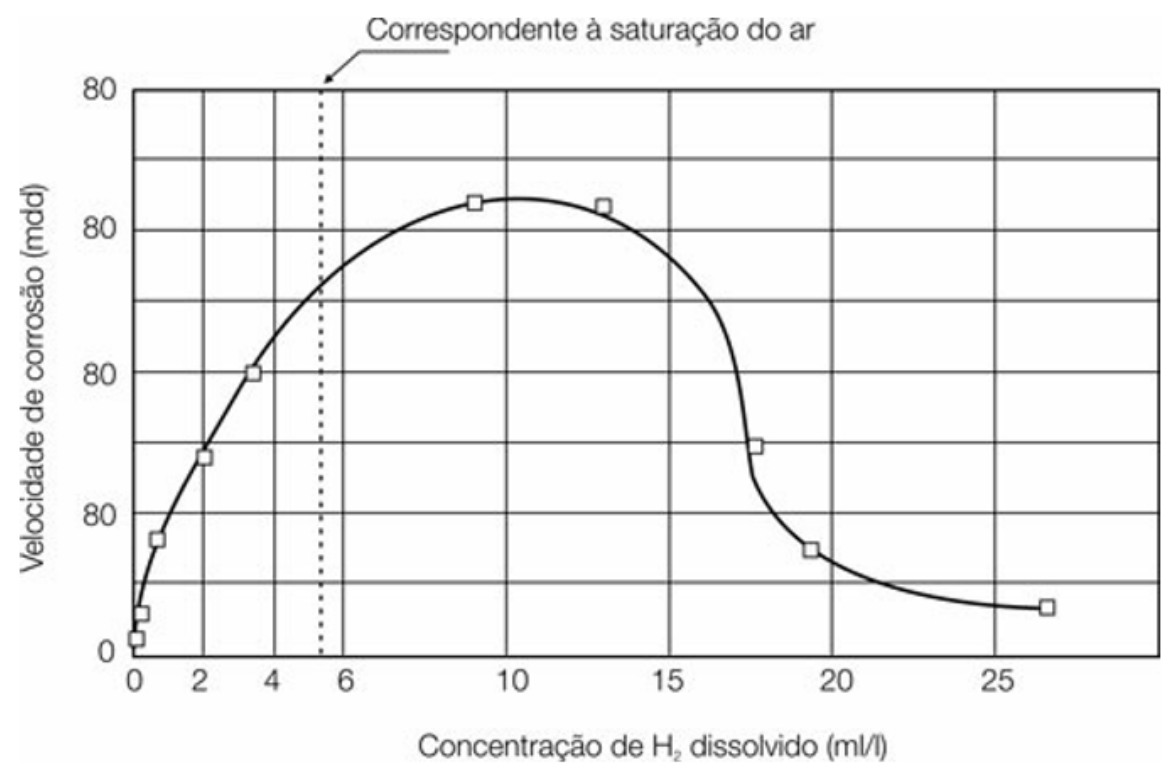

Figura 5 - Velocidade de corrosão em relação à concentração de oxigênio dissolvido (mdd = mg/dm2/dia) (RIBEIRO, 2014).

Os agentes agressivos contidos ou absorvidos no concreto podem acelerar a corrosão, já que inibem a formação ou destroem a camada passivadora do aço. Dentre eles estão: íons sulfatos, dióxido de carbono, gás sulfúrico, entre outros.

Tuutti (1982) estabeleceu através de um modelo, uma metodologia de vida útil com base na corrosão das armaduras do concreto por meio de dois subprocessos: iniciação e propagação.

O período da iniciação é determinado pelo cobrimento do concreto, no qual sofrerá alterações devido ao nível de concentração das substâncias que dão início a corrosão. O processo da corrosão começa no estágio da propagação (TUUTTI, 1982). Assim, após a despassivação da armadura, a velocidade e a intensidade da corrosão são determinadas pelas condições termodinâmicas (RIBEIRO, 2014). O teor de umidade é o principal fator de controle do processo.

A umidade no concreto é controlada pela temperatura, sendo que esta, regula a evaporação e a condensação da água no seu interior, cuja a qual, atua como eletrólito no processo de corrosão (RIBEIRO, 2014).

\section{Estruturas de concreto e procedência dos sulfatos}

O concreto quando executado com os devidos cuidados, proporciona baixa permeabilidade, reduz a penetração de agentes agressivos, funcionando como uma barreira para impedir que os vergalhões de aço sofram ataques de íons agressivos, como por exemplo, íons sulfatos.

O desgaste, variações químicas ou alterações na estrutura são devido às alterações sofridas pelo material que estão relacionadas com a interação físico-química entre o material e o meio.

A deterioração e a corrosão do concreto podem ser observadas pelos processos principais, sendo estes, classificados de acordo com a sua natureza, em mecânicos, físicos, químicos, biológicos.

Segundo Metha (2006), reações químicas que envolvem produtos expansivos no concreto podem gerar prejuízos. Em primeiro momento, as expansões podem não gerar danos ao concreto, porém, com o aumento crescente das tensões internas acarreta deformações, deslocamentos em diferentes partes da estrutura, rachaduras, entre outros.

Grandes teores de sulfatos podem ser encontrados nos solos e em águas industriais como naturais (RIBEIRO, 2014). As concentrações de SO4 entre 3.000 e $6.000 \mathrm{mg} / \mathrm{l}$ são consideradas as mais severas (WHITTAKER, 2014). Na maioria dos solos, o sulfato está na forma de gipsita (ou gesso, CaSO4.2H2O), geralmente em concentrações que variam de $0,01 \%$ a $0,05 \%$ de SO4, sendo, portanto, quantidades inofensivas ao concreto. 
Nas águas subterrâneas, os sulfatos mais presentes são: magnésio, sódio e potássio. O sulfato de amônia pode ser encontrado em águas e terras agrícolas (DE LIMA e SILVA et al., 2018).

\section{Corrosão pelos íons sulfatos}

Geralmente, a agressividade do ataque está ligado ao teor de sulfatos no solo e na água em contato com o concreto e às características desse concreto (RIBEIRO, 2014). Aumentando o teor de sulfatos, aumenta a agressividade do meio, e quando estão dissolvidos em água, esses íons se tornam mais agressivos (RIBEIRO, 2014).

A Figura 6 abaixo, demonstra que ataque por sulfato ao concreto provoca reações entre o agente agressor e o composto do material cimentício. Segundo Ribeiro (2014), esse ataque ocorre devido à três fatores: penetração dos íons sulfato na matriz do cimento; reação dos sulfatos com o hidróxido de cálcio, formando gesso; e na reação do gesso com os aluminatos, resultando em compostos expansivos, como a etringita.

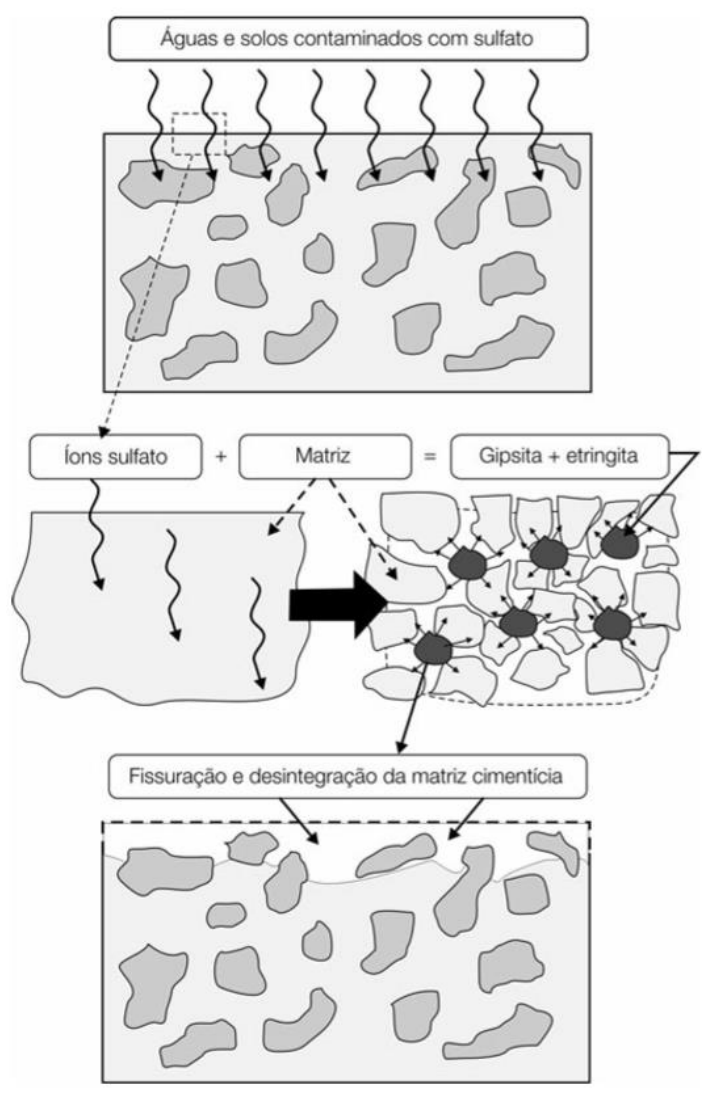

Figura 6 - Representação esquemática dos efeitos do ataque por sulfatos sobre o concreto (RIBEIRO, 2014).

Os sulfatos mais prejudiciais para o concreto são: sulfato de amônio [(NH4)2SO4], o sulfato de cálcio (CaSO4), o sulfato de magnésio (MgSO4) e o sulfato de sódio ( $\mathrm{Na2SO} 4$ ).

Dentre eles, o sulfato de magnésio, por sua vez, é o mais prejudicial devido à formação de hidróxido de magnésio, e este reage também com o hidróxido de cálcio, reduzindo a alcalinidade do sistema e tornando instável o silicato de cálcio hidratado, que também será alvo de ataque da solução de sulfato (METHA,2006). Pode-se verificar a redução da alcalinidade do sistema, e, consequentemente, a profundidade do ataque, utilizando a fenolftaleína, que é um indicador de basicidade. A partir da Figura 7 abaixo, é possível perceber que, a região acometida pelo ataque de sulfato, apresenta aspecto incolor, enquanto a região não acometida possui aspecto rosado. 


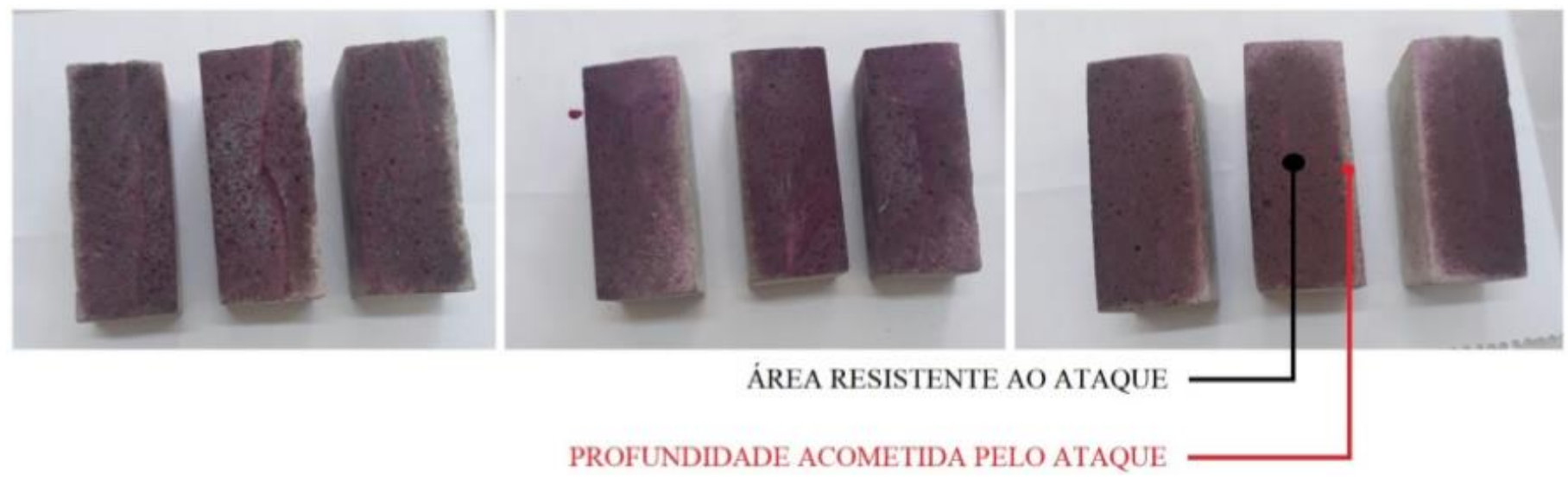

Figura 7 - Efeitos do ataque por sulfatos sobre o concreto (DE LIMA e SILVA et al., 2018).

Assim, diante do projeto estrutural, tem-se o cobrimento do concreto, visualizando então, se o cobrimento já foi ultrapassado ou não pelo ataque de sulfatos, de forma a influenciar diretamente na despassivação do aço que pode acarretar na corrosão do mesmo.

\section{Conclusões}

O conhecimento das manifestações patológicas presentes nas estruturas de concreto armado é de grande importância para que a vida útil de uma estrutura determinada em projeto seja alcançada. $O$ entendimento das origens, das formas de manifestação e os mecanismos de deterioração das estruturas auxilia nas tomadas de decisões no tocante aos procedimentos a serem realizados para garantir a durabilidade e desempenho das das estruturas de concreto armado.

A corrosão das armaduras é o fenômeno mais frequente no que se refere a deterioração das estruturas de concreto armado. Uma das principais causas é o $\mathrm{CO} 2$, que favorece a diminuição do $\mathrm{pH}$ e posteriormente a despassivação da armadura, bem como os íons sulfatos, que também contribuem para esta despassivação.

Fatores como a espessura do concreto e sua qualidade também influenciam na propagação da corrosão, além do meio em que o mesmo está inserido. Por isso, a investigação do solo é primordial para conhecer o nível de contaminação em que a estrutura estará submetida.

$\mathrm{O}$ ataque por sulfatos, conforme citado ao longo deste trabalho, demonstra ser bastante agressivo para as estruturas de concreto armado, alterando as suas características, além de diminuir a sua resistência. Desta forma, a execução das estruturas, por meio das boas técnicas da engenharia, bem como obedecendo as normas vigentes da ABNT, aumentam sua durabilidade.

\section{Referências Bibliográficas}

ABNT - ASSOCIAÇÃO BRASILEIRA DE NORMAS TÉCNICAS. NBR 6118: projeto de estruturas de concreto: procedimento. Rio de Janeiro, 2014.

DE LIMA e SILVA, LD; DE SOUZA, MVT; MARQUES, NM; ALVES, ISSS; GOMES, GJC. Análise da resistividade de estruturas de concreto submetidas ao ataque corrosivo de sulfato de magnésio. Revista Teccen. 2018 Jul./Dez.; 11 (2): 23-31.

FORTES, L.R.; ANDRADE, J.C. Corrosão na armadura do concreto armado: influência dos agentes cloretos e da carbonatação, 2001.

GLASSER, F.P; J. MARCHAND; E. SAMSON. Cem. Concr. Res. 38, 2 (2008) 226.

GENTIL, V. Corrosão. 3 ed. Rio de Janeiro: LTC, 1996.

HELENE, P. R. L. (1986). Corrosão em Armaduras para Concreto Armado, São Paulo: Pini. 
MEHTA, P. K.; MONTEIRO, P.J.M. Concrete: microstructure, properties and materials. Third edition. Publishing company: McGraw-Hill, 2006.

MOTA, J. M. F; PONTES, R. B; CANDEIAS NETO, J. A; OLIVEIRA, M. F; ALMEIDA, H. T; CARNEIRO, A. M. P. Análise das Patologias em Estruturas de Concreto na Zona Litorânea da Cidade do Recife - PE. X Congresso Latinoamericano de Patologia - CONPAT. Valparaiso - Chile. 2009.

MOYSES, R. Durabilidade, Patologia e Recuperação e Recuperação das Estruturas. Apostila para Curso de Especialização, PUC-MG, Belo Horizonte, 2018.

NASCIMENTO, M.L.M; SENA, G.O; NETO, A. C. N; Patologia das Construções. 10 Edição: 2B Educação. 2020.

PEREIRA, V. C. Efeitos dos sulfatos na degradação do concreto. 2019. Monografia (Trabalho de Conclusão de Curso). Universidade Federal da Paraíba, João Pessoa, 2019.

PETRU, M; WANG, X. Mode I fracture evaluation of CFRP-to-concrete interfaces subject to aggressive environments agents: Freeze-thaw cycles, acid and alkaline solution. Elsevier. V. Part B 168. 581-588. 2019.

RIBEIRO, Daniel Verás. Corrosão em Estruturas de concreto armado: teoria, controle e métodos de análise. Rio de Janeiro: Elsevier, 2014.

SILVA, S. S. Diagnóstico de Estruturas de Concreto em Ambientes Marinhos: Estudo de Caso de uma Plataforma de Pesca. 2017. Monografia (Trabalho de Conclusão de Curso). Universidade Federal de Goiás, Goiânia, 2017.

TUUTTI, K. Corrosion of Steel in Concrete. Stokholm: Swedish Cement and Concret Research Institute, 1982.

WHITTAKER, M. Current knowledge of external sulfate attack. Advances in Cement Research. V. 27. Issue 9. 2014. 